\title{
Harmonizing circumpolar monitoring of Arctic fox: benefits, opportunities, challenges and recommendations
}

\author{
Dominique Berteaux ${ }^{a}$, Anne-Mathilde Thierry a,b, Ray Alisauskasc, Anders Angerbjörnd, Eric Buchele, \\ Liliya Doronina ${ }^{f, g}$, Dorothee Ehrich ${ }^{\mathrm{h}}$, Nina E. Eide ${ }^{\mathrm{b}}$, Rasmus Erlandsson ${ }^{\mathrm{d}}, \varnothing$.ystein Flagstad ${ }^{\mathrm{b}}$, Eva Fuglei', \\ Olivier Gilg (1) $\mathbb{e}^{\mathrm{e}, j}$, Mikhail Goltsman ${ }^{\text {, }}$ Heikki Henttonenk, Rolf A. Ims ${ }^{\mathrm{h}}$, Siw T. Killengreen ${ }^{\mathrm{h}}$, \\ Alexander Kondratyev', Elena Kruchenkova ${ }^{9}$, Helmut Kruckenberg ${ }^{m}$, Olga Kulikova ${ }^{\mathrm{n}}$, Arild Landa', \\ Johannes Lang ${ }^{\mathrm{e}, \mathrm{o}}$, Irina Menyushina ${ }^{p}$, Julia Mikhnevich ${ }^{\mathrm{g}}$, Jukka Niemimaa ${ }^{k}$, Karin Norén ${ }^{\mathrm{d}}$, Tuomo Ollila ${ }^{\mathrm{q}}$, \\ Nikita Ovsyanikov ${ }^{p}$, Liya Pokrovskaya ${ }^{g}$, Ivan Pokrovsky', Anna Rodnikova ${ }^{g}$, James D. Roth', Brigitte Sabarde, \\ Gustaf Sameliust, Niels M. Schmidt (10", Benoit Sittlere, ${ }^{\mathrm{e}, \mathrm{v}}$, Aleksandr A. Sokolov ${ }^{\mathrm{n}, \mathrm{w}}$, Natalya A. Sokolova ${ }^{\mathrm{n}, \mathrm{w}}$, \\ Alice Stickneyx, Ester Rut Unnsteinsdóttiry \& Paula A. White
}

aCanada Research Chair on Northern Biodiversity and Centre for Northern Studies, Université du Québec à Rimouski, Rimouski, Québec, Canada; ${ }^{b}$ Norwegian Institute for Nature Research, Trondheim, Norway; 'Prairie and Northern Wildlife Research Centre, Environment Canada, Saskatoon, Saskatchewan, Canada; ${ }^{d}$ Department of Zoology, Stockholm University, Stockholm, Sweden; ${ }^{\text {eArctic Ecology }}$

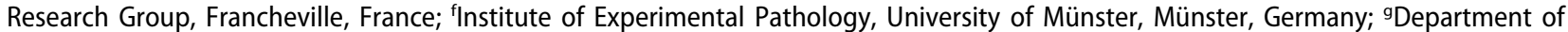

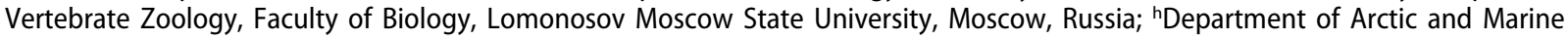

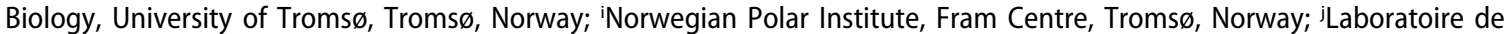

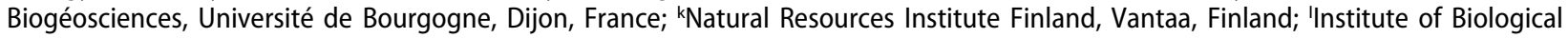
Problems of the North, Far-East Branch Russian Academy of Sciences, Magadan, Russia; ${ }^{m}$ Institute for Waterbird and Wetlands Research,

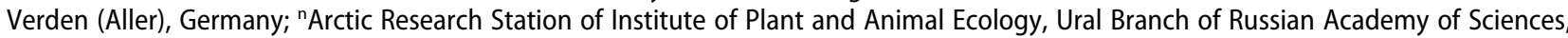

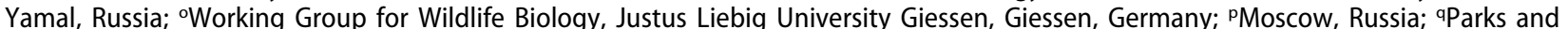
Wildlife, Metsähallitus, Rovaniemi, Finland; 'Department of Migration and Immuno-ecology, Max Planck Institute for Ornithology, Radolfzell, Germany; sDepartment of Biological Sciences, University of Manitoba, Winnipeg, Manitoba, Canada; ${ }^{\mathrm{t} G r i m s o ̈ ~ W i l d l i f e ~}$ Research Station, Swedish University of Agricultural Sciences, Riddarhyttan, Sweden; "Arctic Research Centre, Aarhus University, Roskilde, Denmark; ' ${ }^{\circ}$ Chair for Landscape Management, University of Freiburg, Freiburg, Germany; "Science Center for Arctic Studies, State Organization of Yamal-Nenets Autonomous District, Salekhard, Russia; ‘Ester, AK, USA; ' The Icelandic Institute of Natural History,

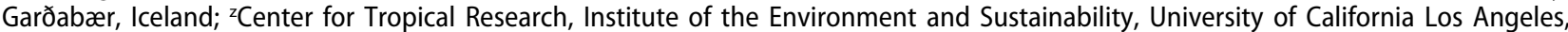
Los Angeles, CA, USA

\section{ABSTRACT}

The biodiversity working group of the Arctic Council has developed pan-Arctic biodiversity monitoring plans to improve our ability to detect, understand and report on long-term change in Arctic biodiversity. The Arctic fox (Vulpes lagopus) was identified as a target of future monitoring because of its circumpolar distribution, ecological importance and reliance on Arctic ecosystems. We provide the first exhaustive survey of contemporary Arctic fox monitoring programmes, describing 34 projects located in eight countries. Monitored populations covered equally the four climate zones of the species' distribution, and there were large differences between populations in long-term trends, multi-annual fluctuations, diet composition, degree of competition with red fox and human interferences. Den density, number of active dens, number of breeding dens and litter size were assessed in almost all populations, while projects varied greatly with respect to monitoring of other variables indicative of population status, ecosystem state or ecosystem function. We review the benefits, opportunities and challenges to increased integration of monitoring projects. We argue that better harmonizing protocols of data collection and data management would allow new questions to be addressed while adding tremendous value to individual projects. However, despite many opportunities, challenges remain. We offer six recommendations that represent decisive progress toward a better integration of Arctic fox monitoring projects. Further, our work serves as a template that can be used to integrate monitoring efforts of other species, thereby providing a key step for future assessments of global biodiversity.

\section{KEYWORDS}

Alopex lagopus; Arctic ecosystems; biodiversity assessment; biodiversity indicator; data management; protocol harmonization

\section{ABBREVIATIONS}

CAFF: Conservation of Arctic Flora and Fauna; IUCN: International Union for Conservation of Nature
The Arctic is in a state of rapid environmental transitions, with a plethora of derived ecological effects (Post et al. 2009). In this context, pan-Arctic biodiversity monitoring is critical to detect, understand and report on biodiversity changes (Meltofte 2013). CAFF, the biodiversity working group of the Arctic Council, has developed circumpolar biodiversity monitoring plans for the marine, terrestrial, freshwater and coastal ecosystems (Petersen et al. 2004; Barry et al. 2013). However, successful implementation of these plans

CONTACT Dominique Berteaux $\otimes$ dominique_berteaux@uqar.ca $\Theta$ Canada Research Chair on Northern Biodiversity and Centre for Northern Studies, Université du Québec à Rimouski, 300 Allée des Ursulines, Rimouski, Québec G5L 3A1, Canada.

(4) Supplemental data for this article can be accessed here. 
will entail overcoming considerable challenges due to the fragmentary and incomplete monitoring capacity in the Arctic. In particular, most Arctic biodiversity initiatives are national or sub-national in scope, while the field protocols and data reporting and archiving techniques of existing monitoring programmes are heterogeneous. For these reasons, there is a need to establish circumpolar connections among teams monitoring similar ecological indicators, and to harmonize methods as much as possible to enable robust, integrated panArctic data analysis and reporting.

Petersen et al. (2004) identified 11 important criteria for selecting possible ecological indicators in the Arctic region. Meeting the following criteria, the Arctic fox (Vulpes lagopus) was identified as one target species for future monitoring (Christensen et al. 2013): generalist feeding regime both potentially impacting and reflecting the state of the tundra ecosystem (Ehrich et al. 2015); circumpolar distribution and reliance on Arctic ecosystems (Angerbjörn \& Tannerfeldt 2014); endangered status in parts of its range (e.g., IUCN's Red List in Europe; Temple \& Terry 2007); flagship status for measuring climate change (IUCN 2009); economic, scientific or cultural importance (Gagnon \& Berteaux 2009); the availability of historical data on the species (e.g., Hersteinsson \& Macdonald 1992; Gallant et al. 2012); and the existence of national monitoring programmes already in place (Herfindal et al. 2010).

The objective of individual Arctic fox monitoring programmes can be to support advances in basic ecological science and/or to address specific conservation concerns, e.g., evaluation of population status. A healthy Arctic fox population might also require a monitoring programme for management of hunting and trapping or to evaluate exploitation of resources affecting the species. Depending on the objectives, the focus of the monitoring may be at the ecosystem, species, population or individual scale.

Our goal is to survey contemporary Arctic fox monitoring projects and reflect on the harmonization of their methods and databases. To achieve this goal, we identified four objectives: (1) to survey and describe all contemporary Arctic fox monitoring projects; (2) to summarize the benefits that could be derived through better integration of these projects; (3) to describe the opportunities for such integration; and (4) to identify the challenges of harmonizing methods and databases. We conclude with recommendations to better integrate current and future Arctic fox monitoring programmes. Our approach may serve as a template for improved integration of data collection for other species or other indicators of biodiversity.

\section{Methods}

We define Arctic fox monitoring as the process of gathering information about some variables describing an Arctic fox population and its ecological context, at different points in time, to assess the status of the population and draw inferences about its changes over time (adapted from Yoccoz et al. 2001). We follow Krebs (2008) in defining a population as a group of individuals occupying a particular space (here, a study area) at a particular time (here, a monitoring period).

An informal circumpolar network of Arctic fox biologists was established through four international conferences in Arctic fox biology that took place in Sweden (1991 and 2009), the UK (2001) and Iceland (2013), as well as through the 2007-09 International Polar Year project Arctic Wildlife Observatories Linking Vulnerable Ecosystems (Gauthier \& Berteaux 2011). Within this informal network, 25 scientists from 10 countries were initially contacted in 2015 through a Google Form survey to collect metadata about contemporary Arctic fox monitoring projects. Sixteen additional scientists (for a total of 41) were invited to participate as active team members of existing projects or when new monitoring efforts were identified. The survey also polled respondents regarding the benefits, opportunities and challenges to integrating Arctic fox monitoring at the circumpolar scale. Data categories and responses were refined when compiling the current synthesis.

Whereas the monitoring of some species is structured according to distinct herds (caribou [Rangifer tarandus]; Russell \& Kofinas 2004), management units (polar bears [Ursus maritimus]; Vongraven \& Peacock 2011) or breeding colonies (murres [Uria spp.]; CAFF 1996), no such units are used for Arctic foxes. The global population has weak genetic structure (Dalén et al. 2005; Carmichael et al. 2007; Geffen et al. 2007; Norén et al. 2011), with the exception of the diverged Commander Islands populations (Ploshnitsa et al. 2012; Ploshnitsa et al. 2013). No management regime has identified distinct population clusters at the global scale. Arctic fox monitoring activities are therefore best described using the concept of "monitoring site", where a group of individuals is monitored over multiple years for research or management objectives. A monitoring site usually corresponds to a well-defined study area in which fox dens, which are long-lasting reproductive structures used repeatedly by territorial individuals (Frafjord 2003; Tannerfeldt et al. 2003; Szor et al. 2008), are visited by scientists every year to assess the presence and reproduction of foxes.

Most Arctic fox monitoring sites were easily distinguished from each other as they corresponded to 
discrete study areas used by independent teams of scientists. In Fennoscandia, however, Arctic fox distribution is fragmented into $>25$ units that sometimes have unclear boundaries between them (Herfindal et al. 2010). Monitoring has been conducted by several teams with various objectives and levels of effort, and monitored units have been under various management regimes. We therefore identified a posteriori 12 monitoring sites for Fennoscandia, each being relatively homogeneous in terms of monitoring history, scientific objectives and management regime. This allowed effective comparison of Arctic fox monitoring activities in Fennoscandia with those from other parts of the world.

The large-scale monitoring performed in Iceland represented a special case because it relied mostly on fox hunting at dens to reduce economic losses associated with sheep (Ovis aries) husbandry and harvesting of down from eider (Somateria mollissima) colonies (Hersteinsson 1992). We included Iceland in our survey despite this methodological singularity, although we excluded Icelandic data from some analyses.
We use the terms "harmonization" and "standardization" as synonyms throughout the paper. All summary statistics are presented as mean \pm standard deviation.

\section{Description of Arctic fox monitoring projects}

\section{Spatial distribution and field effort}

Our synthesis includes 34 Arctic fox monitoring sites located in eight countries. It represents an exhaustive inventory of contemporary monitoring activities for the species. Study areas are distributed throughout the circumpolar North, with a geographic concentration of activities in Fennoscandia (35\% of projects; Fig. 1), where the species is categorized by the IUCN as Critically Endangered in mainland Norway, Sweden and Finland (Hersteinsson et al. 2007; Liukko et al. 2010) on account of overharvest in the early 20th century (Angerbjörn et al. 2004). Remarkably, monitoring projects cover equally the four climate zones of the species' distribution, with 10 or 11 study areas overlapping each of the High Arctic, Low Arctic, Sub-Arctic and Montane/Alpine

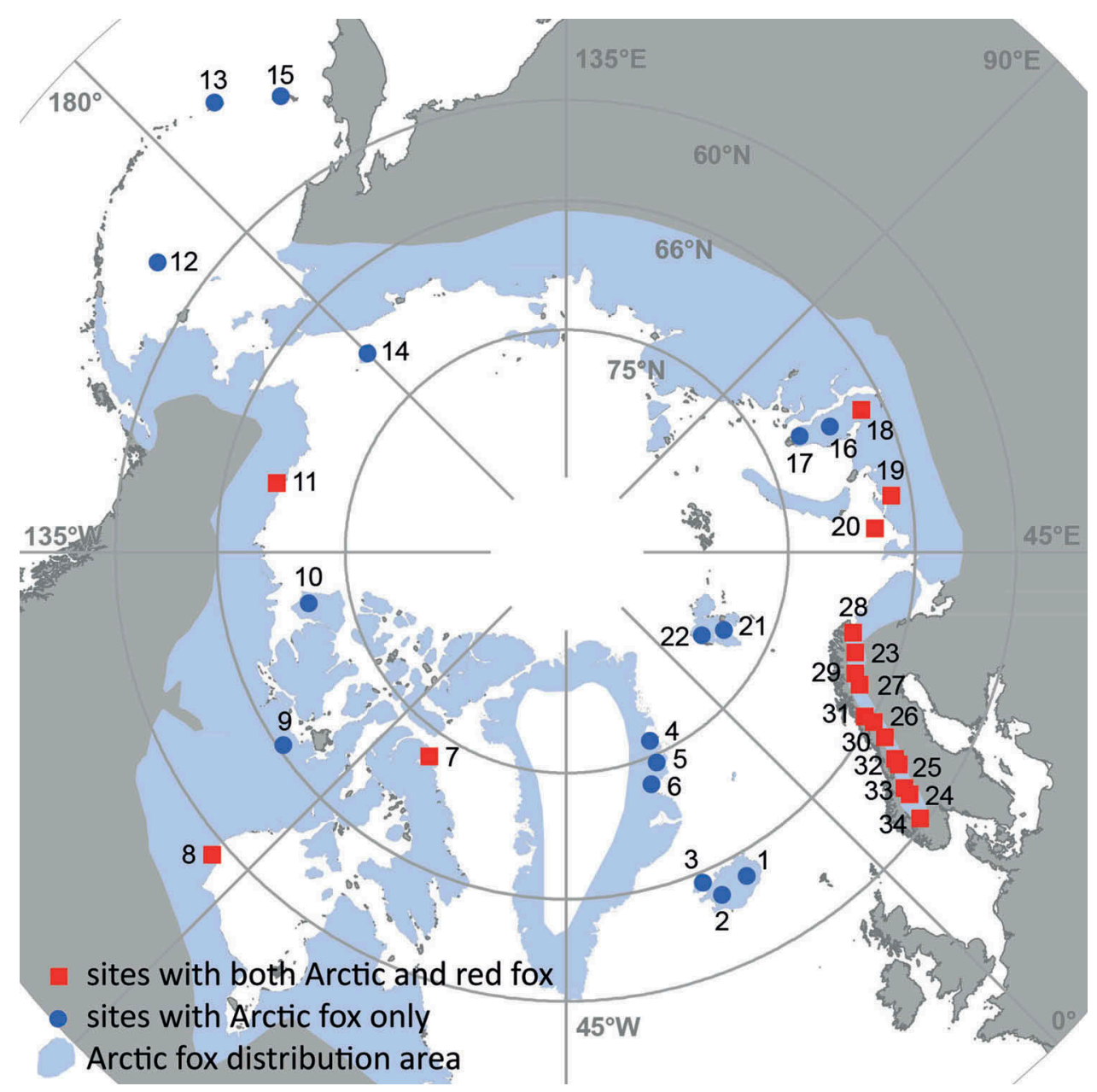

Figure 1. Study sites of the 34 Arctic fox monitoring projects described in this paper (Arctic fox distribution area modified from Angerbjörn \& Tannerfeldt 2014). For study area names, see Table 1. 
climate zones (Supplementary Table S1). This results in a considerable spread of monitoring projects across the temperature/precipitation environmental breadth of northern ecosystems (Fig. 2a). For example, the mean annual temperature of study areas ranges from $-15^{\circ} \mathrm{C}$ (Bylot Island) to $3.7^{\circ} \mathrm{C}$ (Shemya Island), whereas the total annual precipitation ranges from $96 \mathrm{~mm}$ (Egg River) to $1300 \mathrm{~mm}$ (Helags) (Fig. 2a; see Table 1 for study site names). Similarly, the mean temperature of July, which is a good predictor of bioclimatic tundra sub-zones (Walker et al. 2005), varies widely across study sites (Fig. 2b), from $0.7^{\circ} \mathrm{C}$ at Karupev to $13^{\circ} \mathrm{C}$ at Nenetsky.

The size of study areas and the number of known dens also varied greatly between projects (Supplementary Table S1), with densities of known dens varying 100-fold, from 0.01 dens $\mathrm{km}^{-2}$ (Ifjordfjellet/Reisa/Dividalen) to 1 den $\mathrm{km}^{-2}$ (Shemya Island) $\left(\right.$ mean $=0.18 \pm 0.25$ dens $\mathrm{km}^{-2}$ ). Note that in stony areas Arctic foxes can give birth and raise pups in hard-to-detect dens located under boulders, so that numbers of known dens represent minimum counts. The 34 projects ranged in duration from two to 56 years (Fig. 3a), with 27 of them (79\%) still ongoing in 2015 . When combined, the 34 projects totalled 708 years of monitoring at the end of 2015. Projects typically concentrated fieldwork during summer (Fig. 3b) and field effort averaged $155 \pm 130$ person-days per year (Fig. 3c).

\section{Ecological context of monitored populations}

The ecology of the 34 monitored populations was highly variable with regards to long-term trends, multi-annual fluctuations, diet composition, degree of competition with red fox (Vulpes vulpes) and main human interferences (Supplementary Table S2). Over the monitoring periods, long-term population trends were stable (17 populations, 50\%) or increasing (nine populations, $26 \%$ ), with only three populations (9\%) decreasing, although trend was unclear in five cases (15\%). Most populations showed strong multi-annual fluctuations (22 populations, $64 \%$ ), while nine showed no such fluctuations and three showed weak or unclear fluctuations. As expected from the literature (Angerbjörn et al. 1999; Gauthier et al. 2013), most (90\%; 20 out of 22) of the populations showing strong multi-annual fluctuations fed mainly on lemmings (e.g., Lemmus lemmus, L. trimucronatus, Dicrostonyx groenlandicus), whereas $89 \%$ (eight of nine) of the populations showing no multi-annual fluctuations fed primarily on birds, marine food or large mammal carcasses (Supplementary Table 2). As anticipated (Audet et al. 2002), the feeding regime of Arctic foxes was diverse, including terrestrial and marine diets comprising many species of mammals, birds, invertebrates and fish (Supplementary Table 2).

Competition with red fox is a growing pressure on many Arctic fox populations (Hersteinsson \& Macdonald 1992; Henttonen et al. 2007; Killengreen (a)

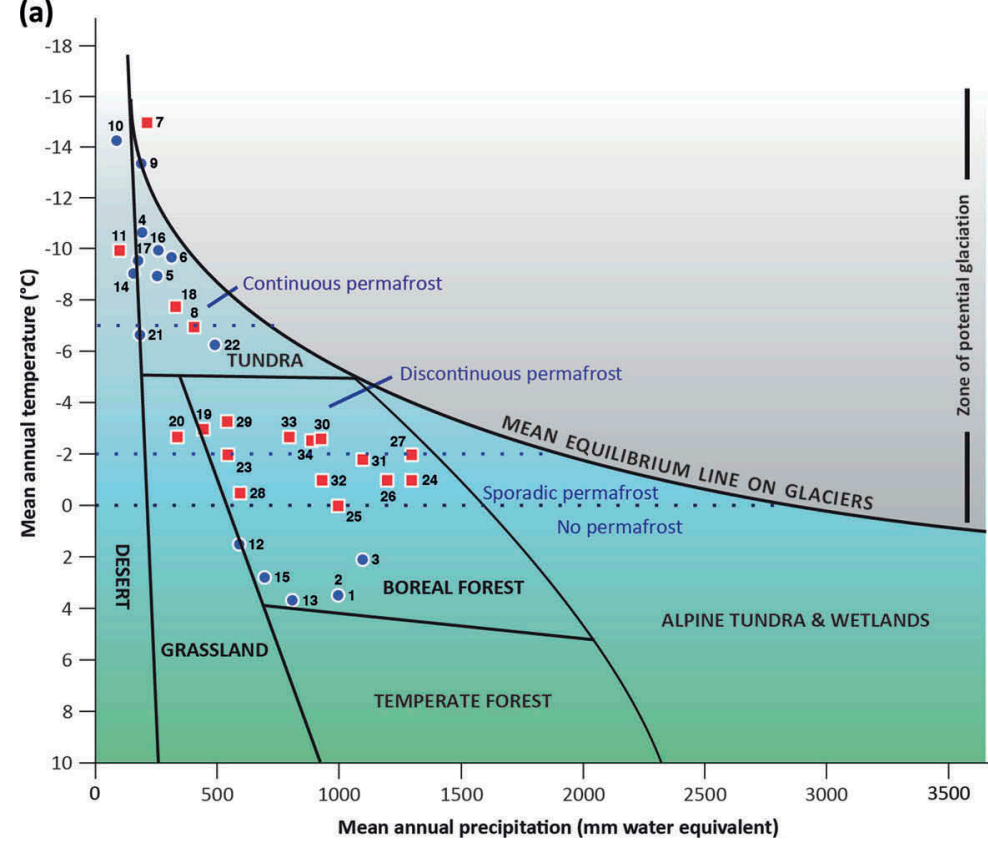

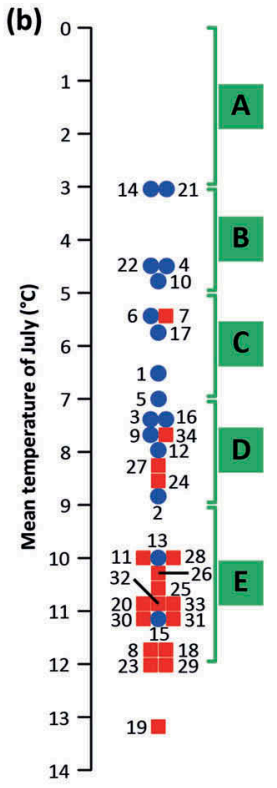

Figure 2. Location of Arctic fox monitoring sites with respect to major climatic and ecological gradients. Blue dots represent sites with Arctic fox only and red squares sites with both Arctic and red fox. For study area names, see Table 1. (a) Location of sites in the temperature-precipitation environmental space. Indicated biome types are theoretical expectations and do not always fit local conditions (for example, no Arctic fox population actually lives in boreal forests). Diagram modified from Elger et al. (2012). (b) Mean July temperature at monitoring sites and corresponding bioclimatic tundra sub-zones (A-E; Walker et al. 2005). Temperatures were extracted from Hijmans et al. (2005) except for sites 4 (Cappelen 2012), 5 (Jensen et al. 2014), 6 (Rau 1995), 11 (August temperature, WeatherSpark 2016 ) and 15 (August temperature, Goltsman, Kruchenkova, Sergeev, Johnson et al. 2005). Indicated tundra sub-zones are theoretical expectations and do not always fit local conditions. 
Table 1. Summary of Arctic fox monitoring sites. Details about identification of sites and delineation of areas are provided in Supplementary Table S1. Sites are mapped in Fig. 1.

\begin{tabular}{|c|c|c|}
\hline $\begin{array}{l}\text { Site reference number } \\
\text { and name }\end{array}$ & Region & Country \\
\hline 1. East Iceland & Eastern regions of Iceland & Iceland \\
\hline 2. West Iceland & Western regions of Iceland & Iceland \\
\hline 3. Hornstrandir & Westfjords & Iceland \\
\hline 4. Kap Rink & Hochstetter Forland & Greenland \\
\hline 5. Zackenberg Valley & Wollaston Forland & Greenland \\
\hline 6. Karupelv Valley & Traill Island & Greenland \\
\hline 7. Bylot Island & Nunavut & Canada \\
\hline 8. Churchill & Manitoba & Canada \\
\hline 9. Karrak Lake & Nunavut & Canada \\
\hline 10. Egg River & Northwest Territories & Canada \\
\hline 11. Prudhoe Bay & Alaska & USA \\
\hline 12. Pribilof Islands & Pribilof Islands & USA \\
\hline 13. Shemya Island & Aleutian Islands & USA \\
\hline 14. Wrangel Island & Chukotka & Russia \\
\hline 15. Mednyi Island & Commander Islands & Russia \\
\hline 16. Sabetta & Yamal Peninsula & Russia \\
\hline 17. Belyi Island & Yamal Peninsula & Russia \\
\hline 18. Erkuta & Yamal Peninsula & Russia \\
\hline 19. Nenetsky & Nenets Autonomous Okrug & Russia \\
\hline 20. Kolguev Island & Nenets Autonomous Okrug & Russia \\
\hline 21. Longyear-byen & Svalbard & Norway \\
\hline 22. Ny-Âlesund & Svalbard & Norway \\
\hline 23. Finnish Lapland & Lapland & Finland \\
\hline 24. Helags & Jämtland & Sweden \\
\hline 25. Borga & Jämtland/Västbotten & Sweden \\
\hline 26. Vindelfjällen/Arjeplog & Västerbotten/Norrbotten & Sweden \\
\hline 27. Norrbotten & Norrbotten & Sweden \\
\hline 28. Varanger & Varanger Peninsula & Norway \\
\hline 29. Ifjordfjellet/Reisa/Dividalen & Troms/Finnmark & Norway \\
\hline 30. Saltfjellet & Nordland & Norway \\
\hline 31. Børgefjell & Nordland/Nord-Trøndelag & Norway \\
\hline 32. Lierne/Sylane & Nord-Trøndelag/Sør-Trøndelag & Norway \\
\hline 33. Snøhetta/Knutshø/Finse & Sør-Trøndelag/Oppland/Buskerud & Norway \\
\hline 34. Hardangervidda & Buskerud/Sogn/Hordaland & Norway \\
\hline
\end{tabular}

et al. 2012; Gallant et al. 2014; Stickney et al. 2014; Elmhagen et al. 2015). Arctic foxes lived in sympatry with red foxes in 18 (53\%) of the 34 monitored populations (Fig. 1), mostly at study sites where summer temperatures were above $8^{\circ} \mathrm{C}$ (Fig. 2b). In sympatric settings, the proportion of Arctic to red foxes in the study area ranged from $<1 \%$ (Finnish Lapland) to $>97 \%$ (Bylot Island) as estimated from the maximum numbers of Arctic and red fox breeding pairs observed in the study area (Supplementary Table S2).

Human interferences with Arctic foxes were also found to be variable both in terms of magnitude and effect. In nine of 34 populations (26\%), no measured or suspected effects of humans on population size or trend were reported (Supplementary Table S2). In other populations, human interferences were all positive (14 populations), all negative (four) or a combination of positive and negative (five). Eleven of 14 projects reporting only positive human interferences were from Fennoscandia, where considerable conservation actions were undertaken over the last decades (Angerbjörn et al. 2013). Supplementary Table S2 shows that human interferences take many forms, from feeding (14 populations) to removal of competitors (seven populations) and release of captive-bred individuals (three populations) in the case of positive interferences, and from direct killing of individuals (10 populations) to transmission of diseases from pets (two populations) in the case of negative interferences. Additionally, some human interferences, e.g., feeding, may constitute positive interference when conducted as a controlled part of a fox conservation programme, but represent a negative interference in other circumstances, e.g., foxes feeding on garbage at a dump. One caveat of our analysis of human interferences, however, is that historical (e.g., early 20th century trapping) and global (e.g., climate change) human interferences were not taken into account.

\section{Monitoring objectives, techniques and variables}

Nineteen (56\%) of the 34 Arctic fox monitoring projects included management objectives usually referred to as "conservation". In $89 \%$ of the projects citing management objectives, management of Arctic fox was the primary goal (Supplementary Table S3).

Few projects attempted to mark and follow individual foxes; tagging of individuals was conducted in only six (18\%) populations. The Mednyi Island project was unique in monitoring the life histories of a large representative sample (up to $80 \%$ ) of individually recognizable animals over several generations (Goltsman, Kruchenkova, Sergeev, Volodin et al. 2005; Kruchenkova et al. 2009). 

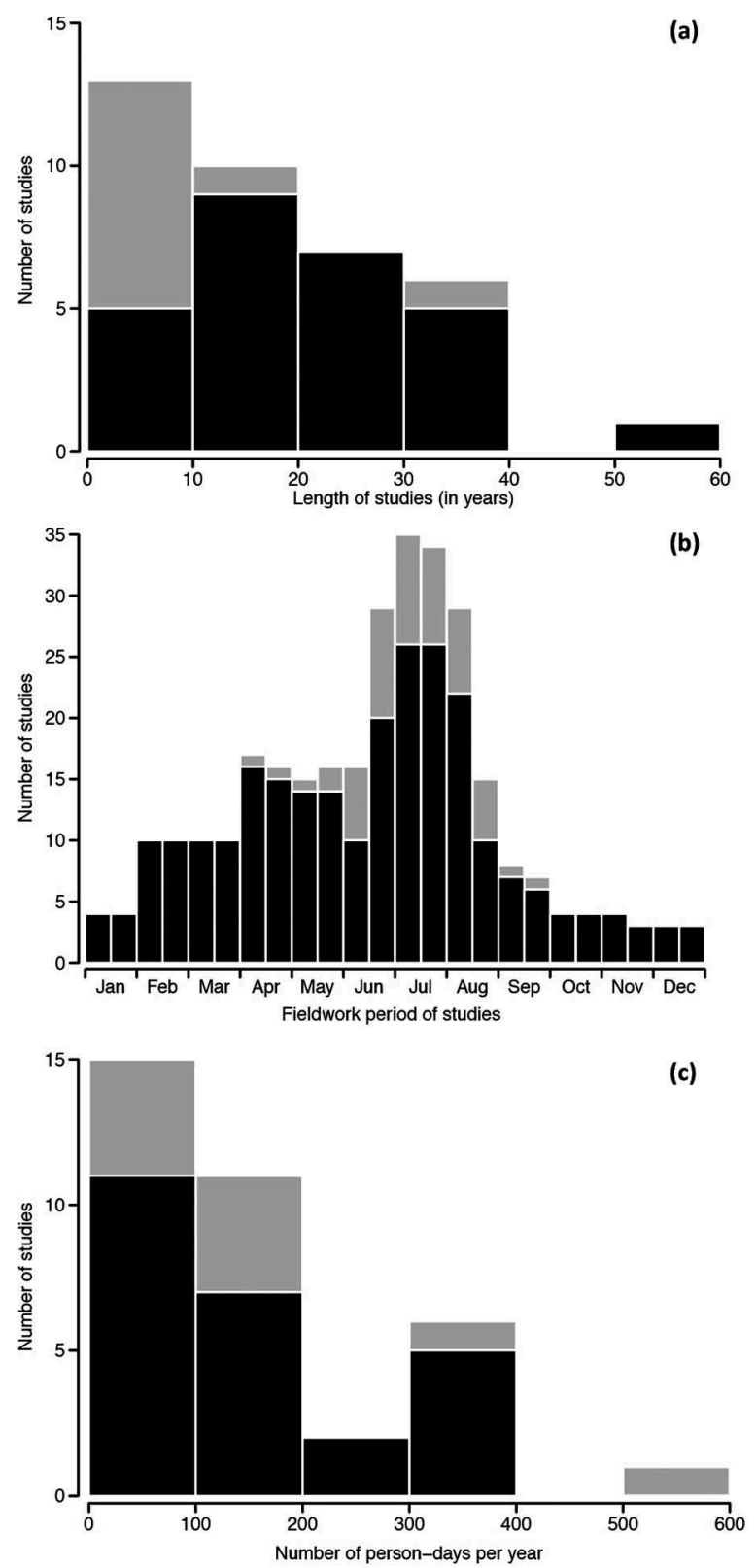

Figure 3. (a) Duration of studies, (b) fieldwork period of studies and (c) field data collection effort for $34(a, b)$ and 32 (c) of the 34 studies included in this paper. For the Bylot Island, Churchill and Kolguev Island sites, data from the longest monitoring period appear in (b) and (c). Projects still active in 2015 are indicated in black whereas projects completed before 2015 are indicated in grey.

In assessing population status, the three most commonly monitored variables were fox abundance, reproductive effort and litter size. These variables were assessed in almost all projects, usually by conducting a total census of dens in the study area, followed by annual summer assessment of the proportion of dens showing signs of occupancy (active dens) and reproduction (reproductive dens) (Supplementary Table S3). Other variables indicative of population status were monitored, but the extent of coverage differed widely among sites. For example, cub survival and genetic parameters were monitored in $\geq 20$ (59\%) projects, whereas contamination level was monitored in 13 (38\%) projects and disease exposure was monitored in only five (15\%) projects (Supplementary Table S3). Most monitored variables were assessed through multiple techniques, with some, such as diet, monitored using six different methodologies (Supplementary Table S3).

Most projects monitored some variables indicative of ecosystem structure, although these variables differed greatly across populations, reflecting differences in monitoring effort and objective as well as differences in ecosystem structure (e.g., red fox abundance was monitored in 17 of the 18 study areas where red foxes were present but was unnecessary where red foxes were absent). Only 10 (29\%) projects monitored $\geq$ two variables indicative of ecosystem function, such as predation rate of Arctic foxes on bird nests, plant productivity or plant or bird phenology. Finally, 17 (50\%) projects reported that there was substantial local knowledge about the study population, but only three (9\%) routinely collected such information as part of the monitoring programme.

\section{Benefits to project integration}

A full integration of Arctic fox monitoring at the circumpolar scale would combine all existing monitoring efforts into one large project with multiple study areas and study populations, while establishing a single protocol for data collection and management. Such close coordination would be one end-point of the spectrum, the other extreme being a set of fully independently operating projects. The current situation lies somewhere in between, with existing projects influencing each other through exchanges of information, but in many cases without common protocols. Fennoscandia is an interesting exception, with common or very similar protocols being used at multiple sites.

The benefits of greater project integration fall into three categories: (1) easier implementation of current techniques and more rapid uptake of new ones; (2) easier assessment of trends at the circumpolar level; and (3) quicker progress in our scientific understanding of the biology and ecosystem of the Arctic fox. Reviewing these benefits highlights the potential added value that may be achieved through circumpolar-level cooperation beyond what is currently possible through individual efforts.

\section{Techniques}

Coordinated monitoring efforts are more cost effective than multiple, uncoordinated efforts (Christensen et al. 2011). First, data collection techniques relevant to Arctic fox monitoring evolve quickly. For example, cameratraps (Hamel et al. 2013; McCallum 2013), stable isotopes (Angerbjörn et al. 1994; Ben-David \& Flaherty 2012) and satellite tracking (Tarroux et al. 2010; Christin et al. 2015) now allow measurements that were impossible a few 
decades ago, and additional technologies, e.g., automatic classification of camera-trapping images, continue to develop rapidly (Yu et al. 2013). Increased coordination of data collection protocols assists in the timely dissemination of new technology (Barry et al. 2013), and helps to resolve relatively minor differences in protocols that can have large effects on data interpretation.

Second, requirements from funding agencies and scientific journals regarding the archiving, updating, sharing and visualization of data also evolve quickly as they follow changes in digital capacities and public demand (British Ecological Society 2014). Scientists studying Arctic foxes create similar types of data and face similar problems in managing these data. For example, 22 of the 34 described projects use automatic cameras (Supplementary Table S3) and face the same computational and memory challenges when managing image sequences. Coordinating data management protocols would result in substantial economies of scale for individual projects.

\section{Trend assessment}

There is an increasing demand for easily accessible and accurate information on biodiversity trends in the Arctic (Gill et al. 2008). Assembling such information requires integration of circumpolar data on specific indicators of biodiversity.

Our description of Arctic fox monitoring showed that there are long-term data on status, trends and drivers of change for many populations throughout the circumpolar Arctic. Yet there is no assessment of the species taking into account all this available information. For example, Angerbjörn et al. (2012) used data from $<40 \%$ of the projects described in this study (and from only one population located outside Fennoscandia) when reporting on Arctic fox trends at the global level.

The time needed to locate and obtain data from multiple populations, and the difficulties of comparing data across projects, explain this underuse of existing data. Stronger integration of data collection and management protocols is needed to allow large-scale assessment of status and trends for the species.

\section{Scientific understanding}

Harmonization of monitoring projects would facilitate scientific progress in Arctic biology (Petersen et al. 2004). Spatially replicated experiments (Reid et al. 2012) and comparisons along gradients (McKinnon et al. 2010; Legagneux et al. 2014) are powerful approaches to test ecological hypotheses, and common variables assessed over the long term at multiple sites provide an ideal platform to design such studies (Ims et al. 2013). Although there is no clear definition of what constitutes a long-term study, assessment of demographic trends requires at least 10 years of monitoring in Arctic fox populations driven by three- to four-year cyclic outbreaks of tundra rodents.

Because many of the changes affecting Arctic and red foxes have a global perspective it is important that the research and action programmes are coordinated over a global scale (Berteaux et al. 2011). In that respect, the geographic breadth and variability of environmental conditions of monitored Arctic fox populations (Supplementary Tables S1, S2, Figs. 1, 2) offer a wealth of research opportunities.

Research on the evolution of litter size in Arctic foxes (Tannerfeldt et al. 1998), on the genetic structure of Arctic canids (Carmichael et al. 2007; Geffen et al. 2007; Norén et al. 2011), and studies using stable isotopes (Angerbjörn et al. 1994; Ehrich et al. 2015) are among the first works to expose the vast and varied opportunities presented by the diversity of Arctic fox monitoring sites. Development of stronger integration of methods and results across projects has tremendous potential for greater synthesis of data from ongoing monitoring efforts, identification of data gaps and improved efficiency in designing new comparative studies.

Cross-project comparisons also provide for a critical evaluation of the effectiveness of different management actions. For example, Angerbjörn et al. (2013) showed in Fennoscandia that variations in population productivity of Arctic foxes could be explained by coupling replicated management actions to long-term monitoring. This comparison was possible because of the close integration of monitoring activities within Fennoscandia and offers a strong argument for increased project integration at a circumpolar scale. Similarly, the anthropogenic footprint differs across the Arctic and could be used as a comparative factor to assess changes in Arctic fox populations located in impacted versus non-impacted sites (Christensen et al. 2013).

\section{Opportunities to better integrate projects}

To allow future efforts to build from existing strengths, we now describe the circumstances that favour a better integration of Arctic fox monitoring at the circumpolar scale. We see four main opportunities: (1) an informal network of Arctic fox specialists already exists; (2) contemporary monitoring projects share characteristics facilitating increased integration; (3) data sharing capacities are already in place; and (4) initiatives toward increased integration of monitoring activities in the Arctic benefit from a highly supportive institutional environment.

\section{Arctic fox network}

As described in Methods, a circumpolar network of people active in Arctic fox biology and management emerged during the last decades. Strong connections 
were first established in Fennoscandia, where the Arctic fox was protected by law in all countries by 1940 and where the species' situation deteriorated further during the 1980s and 1990s (Angerbjörn et al. 1995; Angerbjörn et al. 2013). This network of university researchers, students, governmental biologists and conservationists then expanded to encompass all northern countries. Although informal at the circumpolar scale, it has allowed exchanges of information between projects through collaborations, conferences and workshops, and visits to field sites.

The existence of such informal networks offers irreplaceable opportunities for further collaborations such as those needed to better integrate monitoring activities through shared protocols. A network contributes to building trust, reciprocity and shared values among its participants. These are important assets to act together effectively towards shared goals (Pelling \& High 2005). In particular, trust among individuals provides people with the confidence to invest in collective activities (such as sharing protocols and data), knowing that others will also do so (Pretty \& Ward 2001). Networks are also critical to attract young scientists into a field of enquiry, because networks efficiently demonstrate the many opportunities for future research in that field.

\section{Characteristics of monitoring projects}

The findings presented in this paper show that considerable experience has been accumulated through individual Arctic fox monitoring projects. For example, data have been collected for $\geq$ 10 years for $26(76 \%)$ of the 34 monitored populations (Fig. 3a); nearly $80 \%$ were still active in 2015 (Supplementary Table S1, Fig. 3). Arctic fox monitoring is, thus, carried out at the circumpolar level by a research community that is both experienced and dynamic. This provides unparalleled opportunities to build on practical field experience and the continuity of research projects in planning future studies.

Another valuable characteristic of projects is the common approach of basing fox population status on den visits. This commonality of a few key variables, i.e., den density, number of active dens, number of breeding dens and litter size, provides a basis for initial harmonizing of protocols. Once harmonization of these basic procedures is established, challenges posed by standardizing more complex variables can be approached with greater chance of success. For example, one complex variable is the measure of fox abundance not based on den visits alone, but also including observations of non-breeding adults which may represent the majority of adults in some years (e.g., Samelius et al. 2011).

\section{Data sharing capacities}

Modern technologies increasingly provide for sharing data for decentralized analyses and visualization. For example, the Polar Data Catalogue is a database that describes and provides access to diverse metadata and data generated by polar researchers, whereas the Arctic Biodiversity Data Service (CAFF 2016) disseminates information on the status and trends in Arctic biodiversity. In the case of Arctic fox, baseline data from monitoring projects in Norway and Sweden are stored in a common database (Rovbase 2017). Having data archived in a centralized repository to which access can be granted and use tracked can greatly expedite data sharing when new collaborations are instigated. For example, several teams use telemetry to collect data on Arctic fox distribution and movement. Although no plan to coordinate these data is currently in place, data portals that allow for downloading of animal movement data already exist and could be readily applied for the purpose of project integration (Max Planck Institute for Ornithology 2016). Arctic research communities interested in sharing data can, thus, launch new projects with the added benefit of building on strong existing platforms.

Researchers may have reservations about providing unrestricted access to their data, as promoted by the Circumpolar Biodiversity Monitoring Program (Christensen et al. 2011). However, controlled sharing, temporary restrictions or partial access can allow researchers to retain publishing rights, providing benefits of data sharing while imparting necessary levels of protection for proprietary data ownership. Fully addressing the topic of data sharing goes beyond the objectives of this paper, but our take-home message is that existing data-sharing capacities create vast opportunities for the integration of Arctic fox monitoring projects. Mills et al. (2015) have discussed in a broader context the benefits of, apprehensions about and solutions for archiving and sharing data from long-term studies.

\section{Institutional environment}

The Intergovernmental Platform on Biodiversity and Ecosystem Services was established in 2012 to strengthen the science-policy interface for the conservation and sustainable use of biodiversity (Díaz et al. 2015). A priority need of this platform is a global system of harmonized biodiversity observations to inform scientists and policy-makers (Pereira et al. 2013). In the Arctic, the Terrestrial Monitoring Plan of the Circumpolar Biodiversity Monitoring Program (Barry et al. 2013) is designed to provide a framework for the harmonization of existing Arctic 
monitoring data in addition to standardizing future terrestrial ecosystem-based biodiversity monitoring.

Because of the wide distribution of the Arctic fox in the circumpolar North, its major role in the trophic dynamics of the tundra, and the strong sensitivity of its relationship to climate change (IUCN 2009), this species is recognized as a focal species for the Circumpolar Biodiversity Monitoring Program. Similarly, the Terrestrial Steering Group of CAFF (2014) has identified Arctic fox as an important species to focus on in the future. There is, therefore, no question that initiatives toward increased integration of Arctic fox monitoring activities will be met with a highly supportive institutional environment.

\section{Challenges to project integration}

Despite clear needs and opportunities, there are also challenges to a better integration of Arctic fox monitoring projects. Some of these challenges are specific to Arctic fox monitoring, whereas others are common to most ecological monitoring. We examine them in turn, with emphasis on heterogeneity across projects in objectives, ecological context, logistics constraints and data management strategies.

\section{Project objectives}

Objectives and priorities of Arctic fox monitoring projects differ. For example, some projects are driven by Arctic fox conservation, with efforts focused on fox monitoring (e.g., Fennoscandian sites). In other cases, where objectives are driven by ecosystem science, fox monitoring may represent one of many project components (e.g., Greenland sites, Erkuta). Size of the area studied, complexity of the data sampled and temporal sustainability of projects also differ according to financial and organizational support. For example, monitoring can be: (1) mostly sustained by volunteer work (Hornstrandir, Karupelv Valley); (2) fit a government mandate and thus benefit from dedicated staff (Longyearbyen, Finnish Lapland); (3) be part of an environmental assessment (Prudhoe Bay); or (4) pertain to an academic project funded through competitive grant proposals (Churchill, Bylot Island). Such a diversity of contexts challenges harmonization of protocols and objectives because interests, resources and long-term commitment of principal investigators differ.

\section{Ecological contexts}

Correlating trends in Arctic fox populations with ecological drivers is only possible if likely drivers of change are measured. Projects should therefore take an ecosystem-based approach and use appropriate hypotheses to guide the selection of drivers that will be monitored (Lindenmayer \& Likens 2009). However, as shown in Supplementary Tables S1 and S2 and Figs. 1 and 2, Arctic foxes use all northern habitats (from polar deserts to oceanic islands and from Arctic sea ice to Alpine tundra) and feed from a highly heterogeneous prey base. As recognized by Christensen et al. (2013), the opportunity to standardize monitoring protocols and hypotheses can therefore be limited by the natural heterogeneity among sites. Given limited funds and time, determining the need-to-have and the nice-to-have in a coordinated fashion is a difficult, although potentially rewarding, task.

\section{Logistic constraints}

The remoteness of many Arctic locations adds unique logistical challenges to information gathering. For example, in Russia there is no national organization coordinating field logistics in support of scientific activities (although this is developing regionally, such as in Yamalo-Nenets Autonomous Okrug). Projects across the Arctic face severe constraints to field logistics that may impede harmonization of data collection protocols. For example, litter size is evaluated in June-July by counting cubs soon after they emerge from the den, at three to four weeks of age (Garrott et al. 1984; Eide et al. 2015). However, because the whole litter is rarely observed simultaneously, litter size estimates increase with time spent observing the den. Ideally, a shared protocol would involve long observation periods at each den (e.g., 24 hours). Unfortunately this is not always compatible with strict helicopter or boat schedules, long walking distances between dens and camp or lack of personnel due to budget constraints.

Long-term funding whereby ecological monitoring is supported for decades without interruptions is another major challenge, as grant committees require continuing evidence that projects are remaining productive and innovative (Lindenmayer \& Likens 2009; Clutton-Brock \& Sheldon 2010). Funding may also be more readily provided for some activities over others. For example, the costs of data collection are easy to demonstrate, while the costs of scientific oversight, training, data management and reporting are often much more difficult to justify to funders (Caughlan \& Oakley 2001).

\section{Data management strategies}

Arctic fox monitoring projects store data on various support platforms, including field notebooks, standard paper forms, Excel tables and Access and SQL databases. These differences in data storage challenge the consolidation of data across projects. In addition, cooperation 
among entities for sharing data is not always straightforward. For example, one oil company operating in the North Slope oilfields of Alaska requires that any request for Arctic fox data go through its legal office to be vetted. Restrictions to sharing data can also differ according to whether a project is based at a university or a government agency.

Adoption of new protocols can break long time-series if data collected with the new protocols cannot be compared to past data. This can be avoided by running the old and new protocols simultaneously and establishing correction factors between time-series, but this entails additional time and financial costs that some projects may be unable to support.

\section{Conclusion}

The data life cycle of a monitoring project contains six components (Fig. 4). Researchers traditionally focus on the first three components of the cycle (create, process and use data; British Ecological Society 2014). However, archiving, sharing and reusing data (components 4-6; Fig. 4) can add tremendous value to individual projects while allowing new questions to be addressed, usually at much larger scales. In particular, our ability to detect, understand and report on long-term change in Arctic biodiversity relies on re-examination of data obtained from monitoring projects conducted at the species level (Meltofte 2013).

Consolidating large amounts of disaggregated data across populations requires that these data are created and processed through standardized protocols, or can be compared by applying tested correction factors. We have reviewed the benefits of increased integration between Arctic fox monitoring projects and have shown that despite many opportunities, a number of challenges remain before project outputs can be efficiently compared.

We conclude with six recommendations that should allow decisive progress toward a better integration of Arctic fox monitoring projects.

An Arctic Fox Network should be formalized to promote and facilitate exchanges of information between Arctic fox monitoring projects. To consolidate trust, reciprocity and shared values among Arctic fox biologists, the network should create a website to present its goals, introduce its participants and study sites, facilitate the organization of conferences and workshops, and stimulate the production of integrative studies such as this one. A first step in this direction was made by purchasing the arcticfox. org web address.

A forum should be created for standardized protocols at all steps of the data life cycle. Once consensus has been reached on a given topic, the protocols should be recommended and made available,

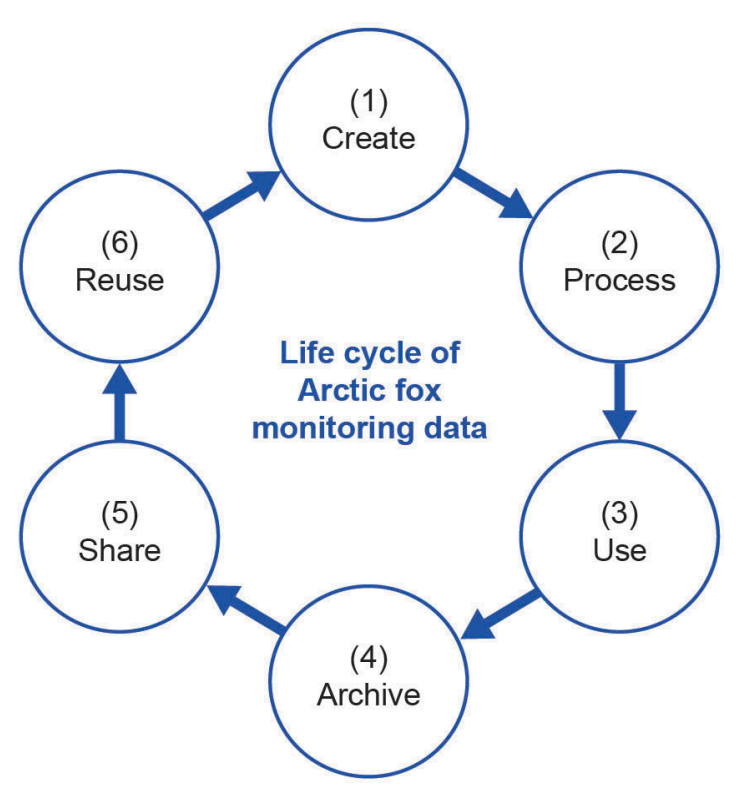

Figure 4. Simplified data life cycle of an Arctic fox monitoring project. Figure modified from British Ecological Society (2014). Available in colour online.

allowing participants to gradually modify and develop correction factors for existing projects or initiate new ones.

The mobility of students and experienced scientists across projects, sharing specialized equipment and writing common grant proposals should be developed to facilitate protocol harmonization.

Archiving, sharing and reusing data should be promoted. This would further encourage harmonization of protocols and add value to individual projects by identifying data gaps and allowing new research designed to address the most pressing needs to be performed.

The use of Arctic fox monitoring data by experts from other fields should be encouraged, as an additional means to add value to projects engaged in data sharing. For example, a listing of biological samples available from all monitoring sites would stimulate new collaborations with toxicologists, geneticists and parasitologists.

Given the status of the Arctic fox as a climate flagship species (IUCN 2009) and the massive climate warming predicted to transform all Arctic ecosystems during the next decades (Meltofte 2013), those variables that are most likely to affect the Arctic fox should be identified for each site. To the extent possible, monitoring of these key variables should be prioritized at all long-term Arctic fox study sites.

\section{Acknowledgements}

We thank the funders and permitting authorities of the 34 described Arctic fox monitoring projects. Although we cannot name all these organizations, their support is much appreciated. We also warmly thank the many people 
who contributed to the data life cycles of the projects. Nicolas Casajus created Figs. 1-4 and Helen Wheeler and the discussion group of the Canada Research Chair on Northern Biodiversity provided helpful comments on an earlier draft.

\section{Disclosure statement}

No potential conflict of interest was reported by the authors.

\section{ORCID}

Olivier Gilg (D) http://orcid.org/0000-0002-9083-4492

Niels M. Schmidt (D) http://orcid.org/0000-0002-4166-6218

\section{References}

Angerbjörn A., Berteaux D. \& Ims R.A. 2012. Arctic fox (Vulpes lagopus). In M. O. Jeffries et al. (eds.): Arctic report card 2012. National Oceanic and Atmospheric Administration, US Department of Commerce. Accessed on the internet at http://www.arctic.noaa.gov/reportcard on 4 April 2016

Angerbjörn A., Eide N.E., Dalén L., Elmhagen B., Hellström P., Ims R.A., Killengreen S., Landa A., Meijer T., Mela M., Niemimaa J., Norén K., Tannerfeldt M., Yoccoz N.G. \& Henttonen H. 2013. Carnivore conservation in practice: replicated management actions on a large spatial scale. Journal of Applied Ecology 50, 59-67.

Angerbjörn A., Hersteinsson P., Liden K. \& Nelson E. 1994. Dietary variation in Arctic foxes (Alopex lagopus) - an analysis of stable carbon isotopes. Oecologia 99, 226-232.

Angerbjörn A., Hersteinsson P. \& Tannerfeldt M. 2004. Arctic fox. In C. Silero-Zubiri et al. (eds.): Canids: foxes, wolves, jackals and dogs. Status survey and action plans. Pp. 117-123. Gland: International Union for Conservation of Nature.

Angerbjörn A. \& Tannerfeldt M. 2014. Vulpes lagopus. The IUCN Red List of threatened species: e.T899A57549321. Version 2014.3. Accessed on the internet at http://www. iucnredlist.org/details/899/0 on 11 April 2017

Angerbjörn A., Tannerfeldt M., Bjarvall A., Ericson M., From J. \& Noren E. 1995. Dynamics of the Arctic fox population in Sweden. Annales Zoologici Fennici 32, 55-68.

Angerbjörn A., Tannerfeldt M. \& Erlinge S. 1999. Predator-prey relationships: Arctic foxes and lemmings. Journal of Animal Ecology 68, 34-49.

Audet A.M., Robbins C.B. \& Larivière S. 2002. Alopex lagopus. Mammalian Species 713, 1-10.

Barry T., Christensen T., Payne J. \& Gill M. 2013. Strategic Plan 2013-2017. Phase II implementation of the Circumpolar Biodiversity Monitoring Program. CAFF Monitoring Series Report 8. Akureyri: CAFF International Secretariat.

Ben-David M. \& Flaherty E.A. 2012. Stable isotopes in mammalian research: a beginner's guide. Journal of Mammalogy 93, 312-328.

Berteaux D., Angerbjörn A., Ehrich D., Eide N.E., Fuglei E., Gallant D., Ims R.A., Kruchenkova E., Lecomte N., Menyushina I.E., Norén K., Ovsjanikov N., Rodnikova A. Y., Tarroux A. \& Yoccoz N.G. 2011. Chapter 8. Arctic and red foxes. In G. Gauthier \& D. Berteaux (eds.): ArcticWOLVES: Arctic Wildlife Observatories Linking
Vulnerable Ecosystems. Final synthesis report. Pp. 133. Quebec City: Centre for Northern Studies, University of Laval.

British Ecological Society 2014. A guide to data management in ecology and evolution. London: British Ecological Society.

CAFF 1996. International Murre conservation strategy and action plan. Ottawa: CAFF.

CAFF 2016. Arctic Biodiversity Data Service. Accessed on the internet at http://www.abds.is/on on 25 January 2016

Cappelen J. 2012. Weather and climate data from Greenland 1958-2011. Observation data with description. Copenhagen: Danish Meteorological Institute.

Carmichael L.E., Krizan J., Nagy J.A., Fuglei E., Dumond M., Johnson D., Veitch A., Berteaux D. \& Strobeck C. 2007. Historical and ecological determinants of genetic structure in Arctic canids. Molecular Ecology 16, 3466-3483.

Caughlan L. \& Oakley K.L. 2001. Cost considerations for long-term ecological monitoring. Ecological Indicators 1, 123-134.

Christensen T., Payne J., Doyle M., Ibarguchi G., Taylor J., Schmidt N.M., Gill M., Svoboda M., Aronsson M., Behe C., Buddle C., Cuyler C., Fosaa A.M., Fox A.D., Heiðmarsson S., Henning Krogh P., Madsen J., McLennan D., Nymand J., Rosa C., Salmela J., Shuchman R., Soloviev M. \& Wedege M. 2013. The Arctic terrestrial biodiversity monitoring plan. Akureyri: CAFF.

Christensen T., Payne J., Schmidt N.M., Madsen J., Taylor J.J., Doyle M., Gill M., Nymand J., Svoboda M., Rosa M., Shuchman B., Soloviev M., Aronsson M., Paakko E., Heidmarsson S. \& Solberg B.Ø. 2011. Terrestrial expert monitoring plan - background paper. Akureyri: CAFF.

Christin S., St-Laurent M.-H. \& Berteaux D. 2015. Evaluation of Argos telemetry accuracy in the HighArctic and implications for the estimation of homerange size. Plos One 10, e0141999, doi: 10.1371/journal. pone.0141999

Clutton-Brock T. \& Sheldon B.C. 2010. Individuals and populations: the role of long-term, individual-based studies of animals in ecology and evolutionary biology. Trends in Ecology \& Evolution 25, 562-573.

Dalén L., Fuglei E.V.A., Hersteinsson P., Kapel C.M., Roth J.D., Samelius G., Tannerfeldt M. \& Angerbjörn A. 2005. Population history and genetic structure of a circumpolar species: the Arctic fox. Biological Journal of the Linnean Society 84, 79-89.

Díaz S., Demissew S., Carabias J., Joly C., Lonsdale M., Ash N., Larigauderie A., Adhikari J.R., Arico S. \& Báldi A. \& Others 2015. The IPBES conceptual framework - connecting nature and people. Current Opinion in Environmental Sustainability 14, 1-16.

Ehrich D., Ims R.A., Yoccoz N.G., Lecomte N., Killengreen S.T., Fuglei E., Rodnikova A.Y., Ebbinge B.S., Menyushina I.E., Nolet B.A., Pokrovsky I.G., Popov I. Y., Schmidt N.M., Sokolov A.A., Sokolova N.A. \& Sokolov V.A. 2015. What can stable isotope analysis of top predator tissues contribute to monitoring of tundra ecosystems? Ecosystems 18, 404-416.

Eide N.E., Ulvund K., Kleven O., Rød-Eriksen L., Landa A. \& Flagstad Ø. 2015. Arctic fox in Norway 2015. Results from the national monitoring programme for Arctic fox. NINA Rapport 1219. Trondheim: Norwegian Institute for Nature Research. 
Elger K., Opel T., Topp-Jørgensen E. \& Rasch M. (eds.) 2012. INTERACT station catalogue. Aarhus: Danish Centre for Environment and Energy, Aarhus University.

Elmhagen B., Kindberg J., Hellström P. \& Angerbjörn A. 2015. A boreal invasion in response to climate change? Range shifts and community effects in the borderland between forest and tundra. Ambio 44, 39-50.

Frafjord K. 2003. Ecology and use of Arctic fox Alopex lagopus dens in Norway: tradition overtaken by interspecific competition? Biological Conservation 111, 445-453.

Gagnon C.A. \& Berteaux D. 2009. Integrating traditional ecological knowledge and ecological science: a question of scale. Ecology and Society 14, 19.

Gallant D., Reid D.G., Slough B.G. \& Berteaux D. 2014. Natal den selection by sympatric Arctic and red foxes on Herschel Island, Yukon, Canada. Polar Biology 37, 333-345.

Gallant D., Slough B.G., Reid D.G. \& Berteaux D. 2012. Arctic fox versus red fox in the warming Arctic: four decades of den surveys in north Yukon. Polar Biology 35, 1421-1431.

Garrott R.A., Eberhardt L.E. \& Hanson W.C. 1984. Arctic fox denning behavior in northern Alaska. Canadian Journal of Zoology 62, 1636-1640.

Gauthier G. \& Berteaux D. 2011. ArcticWOLVES: Arctic Wildlife Observatories Linking Vulnerable Ecosystems. Final synthesis report. Quebec City: Centre for Northern Studies, University of Laval.

Gauthier G., Bety J., Cadieux M.-C., Legagneux P., Doiron M., Chevallier C., Lai S., Tarroux A. \& Berteaux D. 2013. Long-term monitoring at multiple trophic levels suggests heterogeneity in responses to climate change in the Canadian Arctic tundra. Philosophical Transactions of the Royal Society B 368, article no. UNSP 20120482, doi: $10.1098 /$ rstb.2012.0482

Geffen E., Waidyaratne S., Dalen L., Angerbjoern A., Vila C., Hersteinsson P., Fuglei E., White P.A., Goltsman M., Kapel C.M.O. \& Wayne R.K. 2007. Sea ice occurrence predicts genetic isolation in the Arctic fox. Molecular Ecology 16, 4241-4255.

Gill M.J., Raillard M.C., Zöckler C. \& Smith R.B. 2008. CBMP five-year implementation plan. Developing an integrated and sustained Arctic biodiversity monitoring network. CAFF CBMP Report 14. Akureyri: CAFF.

Goltsman M., Kruchenkova E.P., Sergeev S., Johnson P.J. \& Macdonald D.W. 2005. Effects of food availability on dispersal and cub sex ratio in the Mednyi Arctic fox. Behavioral Ecology and Sociobiology 59, 198-206.

Goltsman M., Kruchenkova E.P., Sergeev S., Volodin I. \& Macdonald D.W. 2005. "Island syndrome" in a population of Arctic foxes (Alopex lagopus) from Mednyi Island. Journal of Zoology 267, 405-418.

Hamel S., Killengreen S.T., Henden J.-A., Eide N.E., RoedEriksen L., Ims R.A. \& Yoccoz N.G. 2013. Towards good practice guidance in using camera-traps in ecology: influence of sampling design on validity of ecological inferences. Methods in Ecology and Evolution 4, 105-113.

Henttonen H., Mela M., Niemimaa J. \& Kaikusalo A. 2007. Naalikannan tilanne ja suojelu Suomessa ja Fennoskandiassa. (Arctic fox in Finland and Fennoscandia: status and conservation). Suomen Riista $53,15-24$.

Herfindal I., Linnell J.D.C., Elmhagen B., Andersen R., Eide N.E., Frafjord K., Henttonen H., Kaikusalo A., Mela M., Tannerfeldt M., Dalén L., Strand O., Landa A. \& Angerbjörn A. 2010. Population persistence in a landscape context: the case of endangered Arctic fox populations in Fennoscandia. Ecography 33, 932-941.

Hersteinsson P. 1992. Demography of the Arctic fox (Alopex lagopus) population in Iceland. In D.R. McCullough \& R.H. Barrett (eds.): International conference on population dynamics and management of vertebrates. Wildlife 2001: populations. Pp. 954-964. London: Elsevier.

Hersteinsson P., Landa A., Eide N.E., Linnell J.D.C., Henttonen H., Tikhonov A. \& Angerbjörn A. 2007. Vulpes lagopus. The IUCN Red List of Threatened Species 2007: e.T899A13090095. Accessed on the internet at http:// www.iucnredlist.org/details/899/1 on 5 December 2016

Hersteinsson P. \& Macdonald D.W. 1992. Interspecific competition and the geographical distribution of red and Arctic foxes Vulpes vulpes and Alopex lagopus. Oikos 64, 505-515.

Hijmans R.J., Cameron S.E., Parra J.L., Jones P.G. \& Jarvis A. 2005. Very high resolution interpolated climate surfaces for global land areas. International Journal of Climatology 25, 1965-1978.

Ims R.A., Jepsen J.U., Stien A. \& Yoccoz N.G. 2013. Science plan for COAT: Climate-ecological Observatory for Arctic Tundra. Fram Center Report Series 1. Tromsø: Fram Centre.

IUCN 2009. Species and climate change: more than just the polar bear. Cambridge: IUCN/Species Survival Commission.

Jensen L.M., Christensen T.R. \& Schmidt N.M. 2014. Zackenberg ecological research operations. 19th Annual Report 2013. Aarhus: Danish Centre for Environment and Energy, Aarhus University.

Killengreen S.T., Strømseng E., Yoccoz N.G. \& Ims R.A. 2012. How ecological neighbourhoods influence the structure of the scavenger guild in Low Arctic tundra. Diversity and Distributions 18, 563-574.

Krebs C.J. 2008. Ecology: the experimental analysis of distribution and abundance. 6th edn. San Francisco: Benjamin Cummings.

Kruchenkova E.P., Goltsman M., Sergeev S. \& Macdonald D. W. 2009. Is alloparenting helpful for Mednyi Island Arctic foxes, Alopex lagopus semenovi? Naturwissenschaften 96, 457-466.

Legagneux P., Gauthier G., Lecomte N., Schmidt N.M., Reid D., Cadieux M.-C., Berteaux D., Bêty J., Krebs C. J., Ims R.A., Yoccoz N.G., Morrison R.I.G., Leroux S.J., Loreau M. \& Gravel D. 2014. Arctic ecosystem structure and functioning shaped by climate and herbivore body size. Nature Climate Change 4, 379-383.

Lindenmayer D.B. \& Likens G.E. 2009. Adaptive monitoring: a new paradigm for long-term research and monitoring. Trends in Ecology \& Evolution 24, 482-486.

Liukko U.-M., Henttonen H., Hanski I.K., Kauhala K., Kojola I. \& Kyheröinen E.-M. 2010. Mammals. In P. Rassi et al. (eds.): The 2010 Red List of Finnish species. Pp. 311-319. Helsinki: Ympäristöministeriö \& Suomen Ympäristökeskus.

Max Planck Institute for Ornithology 2016. Movebank. Accessed on the internet at https://www.movebank.org/ on 30 June 2016

McCallum J. 2013. Changing use of camera traps in mammalian field research: habitats, taxa and study types: camera trap use and development in field ecology. Mammal Review 43, 196-206.

McKinnon L., Smith P.A., Nol E., Martin J.L., Doyle F.I., Abraham K.F., Gilchrist H.G., Morrison R.I.G. \& Bety J. 2010. Lower predation risk for migratory birds at high latitudes. Science 327, 326. 
Meltofte H. (ed.) 2013. Arctic biodiversity assessment. Status and trends in Arctic biodiversity. Akureyri: CAFF.

Mills J.A., Teplitsky C., Arroyo B., Charmantier A., Becker P.H., Birkhead T.R., Bize P., Blumstein D.T., Bonenfant C., Boutin S., Bushuev A., Cam E., Cockburn A., Côté S. D., Coulson J.C., Daunt F., Dingemanse N.J., Doligez B., Drummond H., Espie R.H.M., Festa-Bianchet M., Frentiu F., Fitzpatrick J.W., Furness R.W., Garant D., Gauthier G., Grant P.R., Griesser M., Gustafsson L., Hansson B., Harris M.P., Jiguet F., Kjellander P., Korpimäki E., Krebs C.J., Lens L., Linnell J.D.C., Low M., McAdam A., Margalida A., Merilä J., Møller A.P., Nakagawa S., Nilsson J.-Å., Nisbet I.C.T., van Noordwijk A.J., Oro D., Pärt T., Pelletier F., Potti J., Pujol B., Réale D., Rockwell R.F., Ropert-Coudert Y., Roulin A., Sedinger J.S., Swenson J.E., Thébaud C., Visser M.E., Wanless S., Westneat D.F., Wilson A.J. \& Zedrosser A. 2015. Archiving primary data: solutions for long-term studies. Trends in Ecology \& Evolution 30, 581-589.

Norén K., Carmichael L., Dalén L., Hersteinsson P., Samelius G., Fuglei E., Kapel C.M.O., Menyushina I., Strobeck C. \& Angerbjörn A. 2011. Arctic fox Vulpes lagopus population structure: circumpolar patterns and processes. Oikos 120, 873-885.

Pelling M. \& High C. 2005. Understanding adaptation: what can social capital offer assessments of adaptive capacity? Global Environmental Change 15, 308-319.

Pereira H.M., Ferrier S., Walters M., Geller G.N., Jongman R.H.G., Scholes R.J., Bruford M.W., Brummitt N., Butchart S.H.M., Cardoso A.C., Coops N.C., Dulloo E., Faith D.P., Freyhof J., Gregory R.D., Heip C., Höft R., Hurtt G., Jetz W., Karps D.S., McGeoch M.A., Obura D., Onoda Y., Pettorelli N., Reyers B., Sayre R., Scharlemann J.P.W., Stuart S.N., Turak E., Walpole M. \& Wegmann M. 2013. Essential biodiversity variables. Science 339, 277-278.

Petersen A., Zöckler C. \& Gunnarsdóttir M.V. 2004. Circumpolar Biodiversity Monitoring Program. Framework document. CAFF CBMP Report 1. Akureyri: CAFF.

Ploshnitsa A.I., Goltsman M.E., Happ G.M., Macdonald D.W. \& Kennedy L.J. 2013. Historical and modern neutral genetic variability in Mednyi Arctic foxes passed through a severe bottleneck. Journal of Zoology 289, 68-76.

Ploshnitsa A.I., Goltsman M.E., Macdonald D.W., Kennedy L.J. \& Sommer S. 2012. Impact of historical founder effects and a recent bottleneck on MHC variability in Commander Arctic foxes (Vulpes lagopus). Ecology and Evolution 2, 165-180.

Post E., Forchhammer M.C., Bret-Harte M.S., Callaghan T. V., Christensen T.R., Elberling B., Fox A.D., Gilg O., Hik D.S., Hoye T.T., Ims R.A., Jeppesen E., Klein D.R., Madsen J., McGuire A.D., Rysgaard S., Schindler D.E., Stirling I., Tamstorf M.P., Tyler N.J.C., Van Der Wal R., Welker J., Wookey P.A., Schmidt N.M. \& Aastrup P. 2009. Ecological dynamics across the Arctic associated with recent climate change. Science 325, 1355-1358.

Pretty J. \& Ward H. 2001. Social capital and the environment. World Development 29, 209-227.

Rau F. 1995. Geoökologische und ydrologische Untersuchungen in einem hocharktischen Tundrenökosystem auf Traill Ö, Nordost-Grönland. (Geo-ecological and hydrological investigations in a high altitude tundra ecosystem on Traill Island, north-east Greenland.) Freiburg: Albert Ludwig University of Freiburg.
Reid D.G., Bilodeau F., Krebs C.J., Gauthier G., Kenney A. J., Gilbert B.S., Leung M.C.-Y., Duchesne D. \& Hofer E. 2012. Lemming winter habitat choice: a snow-fencing experiment. Oecologia 168, 935-946.

Rovbase 2017. Carnivore database. Norwegian Environment Agency and Swedish Environmental Protection Agency. Accessed on the internet at http://www.rovbase.se/ on 7 April 2017.

Russell D. \& Kofinas G. 2004. Rangifers expert network monitoring plan. Supporting publication to the CAFF Circumpolar Biodiversity Monitoring Program. Framework document. Akureyri: CAFF.

Samelius G., Alisauskas R.T. \& Larivière S. 2011. Seasonal pulses of migratory prey and annual variation in small mammal abundance affect abundance and reproduction by Arctic foxes. Polar Biology 34, 1475-1484.

Stickney A.A., Obritschkewitsch T. \& Burgess R.M. 2014. Shifts in fox den occupancy in the Greater Prudhoe Bay Area, Alaska. Arctic 67, 196-202.

Szor G., Berteaux D. \& Gauthier G. 2008. Finding the right home: distribution of food resources and terrain characteristics influence selection of denning sites and reproductive dens in Arctic foxes. Polar Biology 31, 351-362.

Tannerfeldt M., Angerbjörn A. \& Angerbjorn A. 1998. Fluctuating resources and the evolution of litter sin the Arctic fox. Oikos 83, 545-559.

Tannerfeldt M., Moehrenschlager A. \& Angerbjörn A. 2003. Den ecology of swift, kit and Arctic foxes: a review. In M.A. Sovada \& L. Carbyn (eds.): The swift fox: ecology and conservation of swift foxes in a changing world. Pp. 167-181. Regina, Saskatchewan: Canadian Plains Research Center.

Tarroux A., Berteaux D. \& Bêty J. 2010. Northern nomads: ability for extensive movements in adult Arctic foxes. Polar Biology 33, 1021-1026.

Temple H.J. \& Terry A. (compilers) 2007. The status and distribution of European mammals. Luxembourg: Office for Official Publications of the European Communities.

Terrestrial Steering Group of CAFF 2014. Arctic terrestrial biodiversity monitoring plan: implementation and work plan. Akureyri, Iceland, February 25-27, 2014. First implentation of the Circumpolar Biodiversity Monotoring Program's Terrestrial Steering Group. CAFF Monitoring Series Report 11. Akureyri: CAFF.

Vongraven D. \& Peacock E. 2011. Development of a panArctic monitoring plan for polar bears. Background paper. CAFF Monitoring Series Report 1. Akureyri: CAFF.

Walker D.A., Raynolds M.K., Daniëls F.J.A., Einarsson E. \& Elvebakk A., Gould W.A., Katenin A.E., Kholod S.S., Markon C.J., Melnikov E.S., Moskalenko N.G., Talbot S.S., Yurtsev B.A. \& the other members of the CAVM Team 2005. The circumpolar Arctic vegetation map. Journal of Vegetation Science 16, 267-282.

WeatherSpark. 2016. Average weather for Shemya Island, Alaska, USA. Accessed on the internet at https://weath erspark.com/averages/33066/Shemya-Island-AlaskaUnited-Stateson 27 June 2016

Yoccoz N.G., Nichols J.D. \& Boulinier T. 2001. Monitoring of biological diversity in space and time. Trends in Ecology \& Evolution 16, 446-453.

Yu X., Wang J., Kays R., Jansen P.A., Wang T. \& Huang T. 2013. Automated identification of animal species in camera trap images. EURASIP Journal on Image and Video Processing 2013, article no. 52, doi: 10.1186/1687-5281-2013-52 